\title{
Introduction
}

\section{Histochemical Technologies for Genomics and Proteomics: Laser Capture Microdissection (LCM) and Tissue Microarray (TMA)}

\author{
Robert Y. Osamura $^{1}$, Susumu Takekoshi ${ }^{1}$, Hiroshi Kajiwara ${ }^{1}$ and Takeo Minematsu ${ }^{1}$ \\ ${ }^{1}$ Department of Pathology, Tokai University School of Medicine, Bohseidai, Isehara, Kanagawa 259-1193, Japan
}

\section{Introduction}

Histochemistry has contributed a great deal not only to the understanding of biological phenomena but also to clinical medicine. Recently developed histochemical techniques include immunohistochemistry (IHC), in situ hybridization (ISH) and fluorescence in situ hybridization (FISH), which help analyze not only the localization of proteins but also molecular changes. The main advantage of histochemistry lies in the analysis of biologic phenomena in the "particular cells". In the study of diseases, it is essential to study the particular "disordered cells", such as cancer cells. For this purpose, recent histochemical technologies such as laser capture microdissection (LCM) and tissue microarray (TMA) are very efficient tools. LCM is a technique which enables us to analyze particular cells for DNA and mRNA changes. TMA is suitable for evaluation of the antibodies for IHC and various molecular probes for ISH or FISH. This article is a technical review of LCM and TMA when we apply them for use in histochemistry for basic science and clinical medicine (Fig. 1).

\section{Laser Capture Microdissection (LCM)}

Development of current quantitative and high-throughput technologies, which allow the automated and rapid screening of the whole genome, transcriptome and proteome, have revolutionized the fields of basic and clinical medicine, particularly cancer genetics. LCM is a new technique which originated from National Institutes of Health (NIH), and was commercially developed through a Collaborative Research and Development Agreement partnership with Arcturus Engineering Inc. [4]. LCM is an easy, extremely fast and versatile method for the isolation of morphologically defined cell populations from complex primary tissues for molecular analyses. The development of LCM technique has facilitated the rigorous identification, isolation and subsequent molecular characterization of a single spe-

Correspondence to: Robert Y. Osamura, M.D., Department of Pathology, Tokai University School of Medicine, Bohseidai, Iseharao, Kanagawa 259-1193, Japan. E-mail: osamura@is.icc.u-tokai.ac.jp cific cell or a portion of tissue from the routine hematoxyline-eosin (H\&E) staining and immunostaining sections [2, $6,8,13,14,25]$. Mutation analysis of genes in cancerous tissue can be examined by LCM method followed by polymerase chain reaction (PCR) single strand conformation polymorphism (PCR-SSCP) or direct sequencing of the PCR product. In addition, DNA microsatellite markers with the loss of heterozygosity $(\mathrm{LOH})$ can be assessed in a tumorous lesion microdissected with LCM [22, 29]. For the analysis of mRNA expression, the LCM-assisted reverse-transcription polymerase chain reaction (RT-PCR) procedure has been available to study the molecular mechanisms of diseases using human tissues. In this research, immunohistochemical staining in addition to H\&E staining is extremely important for the precise identification and isolation of a specific cell. IHC shows the presence of particular antigens for specific cells in the heterogeneous population of the tissue section. In this respect, IHC is more useful for LCM-assisted cell isolation than H\&E-staining.

LCM was first reported by Emmert-Buck et al. [4]. Since its initial use and publication, LCM has been successfully applied to investigate many different tissues by isolating specific cells from among the total heterogeneous cell population. In the initial phase of utilizing LCM, the assessment of genetic changes, which include point mutations and $\mathrm{LOH}$, has been frequently examined [22, 29]. In brief, histologic (H\&E-staining or IHC-staining) paraffin sections of tumorous tissue are dehydrated, the regions of interest in the histological section are selected and overlaid with a film mounted on a cap, and then adhered cells are captured by the film through laser energy. The dissected cells are collected in Eppendorf tubes. Theses cells are subsequently digested by lysis buffer containing detergent and proteinase $\mathrm{K}$, and are submitted for PCR, sequencing, and/or SSCP analysis. The p53 gene is a tumor suppressor gene on the short arm of chromosome 17, which consists of 11 exons and 10 introns. In a wide variety of human tumors, p53 gene mutations have been detected mainly in exons 5, 6, 7 and 8 . Since the isolation of tumor cells from heterogeneous tissue is possible, many reports on p53 mutation analysis using LCM have been published $[3,6,13,18]$. This combination of histochemical approach and molecular biology has been an 
Tissue sections

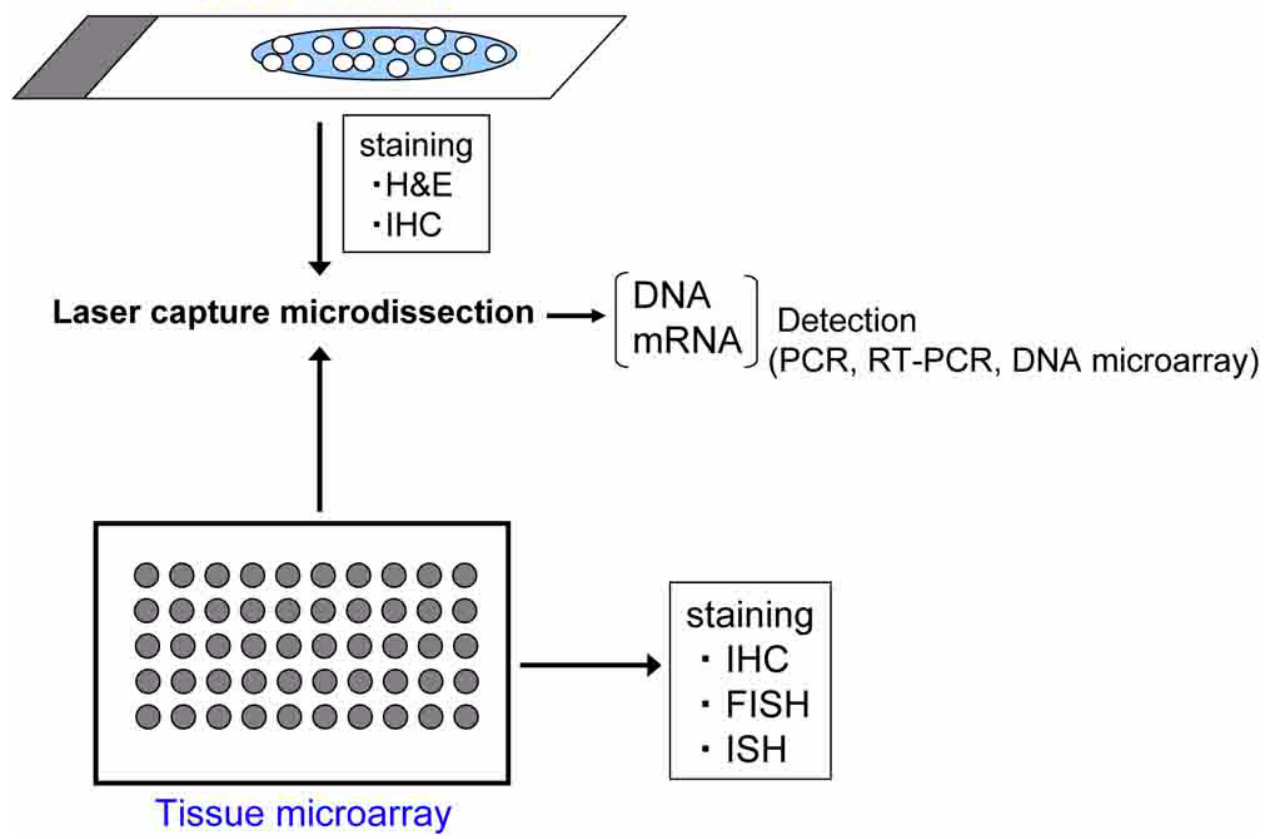

Fig. 1. Schematic diagram of the combination of LCM and TMA techniques.

important contribution to medical science, particularly to cancer research [1, 10, 17, 19, 27, 28].

Investigations of tissue or cell specific gene expressions are important in many fields of biological and biomedical research. The analysis of gene expression patterns related to neoplasia, inflammation, or degenerative disease is important not only for diagnostic and prognostic purposes, but also for preventive medicine by diagnosing subclinical stages of disease, and to target medicine to specific genetic alterations [12]. Using the LCM method, analysis of the differential expressions of genes between normal and disordered cells has been frequently performed [7, 14-16, 24]. Microdissection of tissue sections and cytological preparations using LCM has been used for the isolation of morphologically identified cell populations, thus overcoming the obstacle of tissue complexity. When used alongside sensitive analytical techniques, such as the polymerase chain reaction, LCM allows the precise in vivo examination of cell populations, such as carcinoma in situ, which are otherwise inaccessible for conventional molecular studies [16, 21]. In addition to $\mathrm{H} \& \mathrm{E}$ staining, the using of immunohistochemical stains also allows the precise selection of cells using LCM according to phenotypic and functional characteristics. Thus the combination of LCM-assisted histochemistry and molecular biology has been an important contribution to both basic science and clinical medicine.

Several "high throughput methods", e.g. DNA microarray technology, have been introduced into research and become routine in laboratories during the past decade. LCM has been used in conjunction with DNA microarray analysis to monitor gene expression in individual cells in many tissues [9, 32]. LCM in combination with microarrays facilitates the expression analysis of thousands of genes in selected cells. On the other hand, microarray analysis with the LCM sample requires refined techniques for amplifying mRNA from very small tissue samples. The most widely used method of mRNA amplification is in vitro transcription using T7 RNA polymerase to generate amplified antisense RNA [26]. In brief, first-strand synthesis from the mRNA template and second-strand synthesis with DNA polymerase is followed by $\mathrm{T} 7$ polymerase in vitro transcription to produce large amounts of new transcripts. Recently developed methods of mRNA amplification are more suitable for high throughput requirements and are beginning to supersede the original T7 amplification technique. Template-switching PCR is a method in which a double-stranded template is produced, and subsequently amplified by PCR. It is both faster and more cost-effective for amplifying RNA to be used in microarray experiments [20]. Although it is often desirable to use small starting quantities of RNA, amplification may result in systematic errors caused by transcript profile distortion, depending on the amplification protocol used. However, these errors can be accounted for with analytical techniques [30]. These amplification techniques including a quality assessment system will continue to develop to provide increasingly effective solutions to the problems presented by limited amounts of LCM samples without causing distortion of the expression profile.

\section{Tissue Microarray (TMA)}

Recent proteomics-based studies proffer a powerful complementary approach to DNA/RNA-based investigations. Analysis of the molecular targets in situ at the tissue level and assessment of their expressions across all tissues or diseases would give significant additional information in the 
course of a clinical study. However, conventional histochemical analysis using fresh, frozen or paraffin wax embedded tissues is too expensive and time consuming to be applied to the characterization of hundreds or thousands of gene products associated with distinct tumors entities or other diseases. Tissue Microarray (TMA) is a new technology that enables the rapid analysis of up to 1000 different archival samples $[5,11,23,31]$. Sections from TMA blocks can be used for all different types of histochemical analysis including IHC, FISH, or ISH. TMA technology makes it possible to analyze several hundred samples on a single slide allowing the rapid analysis of genes (ISH) and proteins (IHC). In addition, this technique enables pathologists to perform large-scale analyses faster and at markedly lower costs compared with the conventional morphological approach.

In TMA, most of the working time is consumed with TMA preparation, involving the search, organization, pathological review and processing of the tissue specimens to be embedded in the array, in contrast to the conventional approach. H\&E stained slides corresponding to donor blocks have to be provided. HE-slides have to be reviewed so that appropriate donor blocks can be selected and the region of interest can be defined on a selected paraffin block. Donor tissue blocks should be at least $1 \mathrm{~mm}$ and preferably 3-4 mm thick. Archival blocks dating back 20-40 years are usually adequate if they have been fixed in $4 \%$ buffered formalin. Such specimens can be used for IHC and FISH. On the other hand, ISH is more difficult because of the degradation and cross-linking of RNA molecules by a prolonged series of formalin fixations. Therefore, fixation with $4 \%$ paraformaldehyde or methacarn for 6-12 hr is recommended for ISH on TMA. In general, 0.6-2 mm diameter core biopsies from the donor blocks are used for TMA preparation. In the case of a $0.6 \mathrm{~mm}$ diameter core, the maximum number of samples that can be arrayed in a $45 \times 25 \mathrm{~mm}$ area is about 1000 . Using larger needles, one causes more damage to the original tissue blocks and substantially reduces the number of specimens that can be arrayed. For instance, only about 100-150 cores measuring $2 \mathrm{~mm}$ in diameter can be placed in a single TMA block. It is recommended that TMA is accompanied by the generation of a computer file, containing the tissue block construction and some of the basic clinical data, or the patient identification number if anonymity is required.

\section{Summary}

Histochemistry, as a tool to analyze molecular phenomena at the individual cell level, has contributed to various fields of cell biopsy and clinical medicine. The histochemical detection of molecules has been regarded as a key issue in molecular targeted cancer therapy. In this article, we have reviewed two major histochemical techniques of practical use in molecular biology and molecular medicine, i.e. laser capture microdissection (LCM) and tissue microarray (TMA).

\section{References}

1. Ashida, S., Nakagawa, H., Katagiri, T., Furihata, M., Iiizumi, M., Anazawa, Y., Tsunoda, T., Takata, R., Kasahara, K., Miki, T., Fujioka, T., Shuin, T. and Nakamura, Y. (2004) Molecular features of the transition from prostatic intraepithelial neoplasia (PIN) to prostate cancer: genome-wide gene-expression profiles of prostate cancers and PINs. Cancer Res. 64; 5963-5972.

2. Bonner, R. F., Emmert-Buck, M., Cole, K., Pohida, T., Chuaqui, R., Goldstein, S. and Liotta, L. A. (1997) Laser capture microdissection: molecular analysis of tissue. Science 278; 1481, 1483.

3. Dillon, D., Zheng, K. and Costa, J. (2001) Rapid, efficient genotyping of clinical tumor samples by laser-capture microdissection/PCR/SSCP. Exp. Mol. Pathol. 70; 195-200.

4. Emmert-Buck, M. R., Bonner, R. F., Smith, P. D., Chuaqui, R. F., Zhuang, Z., Goldstein, S. R., Weiss, R. A. and Liotta, L. A. (1996) Laser capture microdissection. Science 274; 998-1001.

5. Hoos, A., Urist, M. J., Stojadinovic, A., Mastorides, S., Dudas, M. E., Leung, D. H., Kuo, D., Brennan, M. F., Lewis, J. J. and Cordon-Cardo, C. (2001) Validation of tissue microarrays for immunohistochemical profiling of cancer specimens using the example of human fibroblastic tumors. Am. J. Pathol. 158; 1245 1251.

6. Ito, S., Ohga, T., Saeki, H., Nakamura, T., Watanabe, M., Tanaka, S., Kakeji, Y. and Maehara, Y. (2005) p53 mutation profiling of multiple esophageal carcinoma using laser capture microdissection to demonstrate field carcinogenesis. Int. J. Cancer 113; 22-28.

7. Jin, L., Tsumanuma, I., Ruebel, K. H., Bayliss, J. M. and Lloyd, R. V. (2001) Analysis of homogeneous populations of anterior pituitary folliculostellate cells by laser capture microdissection and reverse transcription-polymerase chain reaction. Endocrinology 142; 1703-1709.

8. Jin, L., Ruebel, K. H., Bayliss, J. M., Kobayashi, I. and Lloyd, R. V. (2003) Immunophenotyping combined with laser capture microdissection (Immuno-LCM) Acta Histochem. Cytochem. 36; 9-13.

9. Kamme, F., Salunga, R., Yu, J., Tran, D. T., Zhu, J., Luo, L., Bittner, A., Guo, H. Q., Miller, N., Wan, J. and Erlander, M. (2003) Single-cell microarray analysis in hippocampus CA1: demonstration and validation of cellular heterogeneity. J. Neurosci. $23 ; 3607-3615$.

10. Kitahara, O., Furukawa, Y., Tanaka, T., Kihara, C., Ono, K., Yanagawa, R., Nita, M. E., Takagi, T., Nakamura, Y. and Tsunoda, T. (2001) Alterations of gene expression during colorectal carcinogenesis revealed by cDNA microarrays after lasercapture microdissection of tumor tissues and normal epithelia. Cancer Res. 61; 3544-3549.

11. Kononen, J., Bubendorf, L., Kallioniemi, A., Barlund, M., Schraml, P., Leighton, S., Torhorst, J., Mihatsch, M. J., Sauter, G. and Kallioniemi, O. P. (1998) Tissue microarrays for highthroughput molecular profiling of tumor specimens. Nat. Med. 4; 844-847.

12. Lieberman, R., Crowell, J. A., Hawk, E. T., Boone, C. W., Sigman, C. C. and Kelloff, G. J. (1998) Development of new cancer chemoprevention agents: role of pharmacokinetic/pharmacodynamic and intermediate endpoint biomarker monitoring. Clin. Chem. 44; 420-427.

13. Lien, H. C., Lin, C. W., Mao, T. L., Kuo, S. H., Hsiao, C. H. and Huang, C. S. (2004) p53 overexpression and mutation in metaplastic carcinoma of the breast: genetic evidence for a monoclonal origin of both the carcinomatous and the heterogeneous sarcomatous components. J. Pathol. 204; 131-139.

14. Lloyd, R. V., Jin, L., Ruebel, K. H. and Bayliss, J. M. (2002) Analysis of folliculostellate cells by laser capture microdissection and reverse transcription-polymerase chain reaction (LCM-RT/ PCR). Methods Enzymol. 356; 248-255. 
15. Lloyd, R. V. (2004) Advances in pituitary pathology: use of novel techniques. Front. Horm. Res. 32; 146-174.

16. Malhotra, P. S., Malekfzali, A., Bonner, R. F., Juhn, S., Van Waes, C. and Chen, Z. (2004) Assessment of gene expression in head and neck carcinoma using laser capture microdissection and real-time reverse transcription polymerase chain reaction. Laryngoscope 114; 2123-2128.

17. Miura, K., Bowman, E. D., Simon, R., Peng, A. C., Robles, A. I., Jones, R. T., Katagiri, T., He, P., Mizukami, H., Charboneau, L., Kikuchi, T., Liotta, L. A., Nakamura, Y. and Harris, C. C. (2002) Laser capture microdissection and microarray expression analysis of lung adenocarcinoma reveals tobacco smoking- and prognosisrelated molecular profiles. Cancer Res. 62; 3244-3250.

18. Mueller, J., Gansauge, S. and Mattfeldt, T. (2003) P53 mutation but not p16/MTS1 mutation occurs in intraductal papillary mucinous tumors of the pancreas. Hepatogastroenterology 50; 541544.

19. Nakanishi, Y., Mizutani, G., Sano, M., Oinuma, T. and Nemoto, N. (2004) Comparison of HER2 mRNA amplification with immunohistochemistry in human breast cancer using laser assisted microdissection technique. Acta Histochem. Cytochem. 37; 7379.

20. Petalidis, L., Bhattacharyya, S., Morris, G. A., Collins, V. P., Freeman, T. C. and Lyons, P. A. (2003) Global amplification of mRNA by template-switching PCR: linearity and application to microarray analysis. Nucleic Acids Res. 31; e142.

21. Schmid, B. C., Rudas, M., Fabjani, G., Speiser, P., Kaserer, K. Leodolter, S. and Zeillinger, R. (2003) Evaluation of MUC1 splice variants as prognostic markers in patients with ductal carcinoma in situ of the breast. Oncol. Rep. 10; 1981-1985.

22. Shen, C. Y., Yu, J. C., Lo, Y. L., Kuo, C. H., Yue, C. T., Jou, Y. S., Huang, C. S., Lung, J. C. and Wu, C. W. (2000) Genome-wide search for loss of heterozygosity using laser capture microdissected tissue of breast carcinoma: an implication for mutator phenotype and breast cancer pathogenesis. Cancer Res. 60; 3884-3892.

23. Simon, R., Mirlacher, M. and Sauter, G. (2004) Tissue microarrays. Biotechniques 36; 98-105.

24. Smyth, P., Sheils, O., Finn, S., Martin, C., O’Leary, J. and
Sweeney, E. C. (2001) Real-time quantitative analysis of Ecadherin expression in ret/PTC-1-activated thyroid neoplasms. Int. J. Surg. Pathol. 9; 265-272.

25. Trogan, E., Choudhury, R. P., Dansky, H. M., Rong, J. X., Breslow, J. L. and Fisher, E. A. (2002) Laser capture microdissection analysis of gene expression in macrophages from atherosclerotic lesions of apolipoprotein E-deficient mice. Proc. Natl. Acad. Sci. U S A 99; 2234-2239.

26. Van Gelder, R. N., von Zastrow, M. E., Yool, A., Dement, W. C., Barchas, J. D. and Eberwine, J. H. (1990) Amplified RNA synthesized from limited quantities of heterogeneous cDNA. Proc. Natl. Acad. Sci. US A 87; 1663-1667.

27. Wang, X., Nakamura, M., Mori, I., Takeda, K., Suzuma, T., Yoshimura, G., Sakurai, T. and Kakudo, K. (2003) Comparison of gene expression in breast cancer using laser capture microdissection and quantitative RT-PCR. Acta Histochem. Cytochem. 36; 421-425.

28. Wang, X., Nakamura, M., Mori, I., Takeda, K., Nakamura, Y., Utsunomiya, H., Yoshimura, G., Sakurai, T. and Kakudo, K. (2004) Calcitonin receptor gene and breast cancer: quantitative analysis with laser capture microdissection. Breast Cancer Res. Treat. 83; 109-117.

29. Werness, B. A., Parvatiyar, P., Ramus, S. J., Whittemore, A. S., Garlinghouse-Jones, K., Oakley-Girvan, I., DiCioccio, R. A., Wiest, J., Tsukada, Y., Ponder, B. A. and Piver, M. S. (2000) Ovarian carcinoma in situ with germline BRCA1 mutation and loss of heterozygosity at BRCA1 and TP53. J. Natl. Cancer Inst. 92; 1088-1091.

30. Wilson, C. L., Pepper, S. D., Hey, Y. and Miller, C. J. (2004) Amplification protocols introduce systematic but reproducible errors into gene expression studies. Biotechniques 36; 498-506.

31. Zhang, D., Salto-Tellez, M., Putti, T. C., Do, E. and Koay, E. S. (2003) Reliability of tissue microarrays in detecting protein expression and gene amplification in breast cancer. Mod. Pathol. $16 ; 79-84$.

32. Zirlinger, M. and Anderson, D. (2003) Molecular dissection of the amygdala and its relevance to autism. Genes Brain Behav. 2; 282-294. 